Vol 6 / Issue 1 / Jan-Feb 2016

Journal of

International Society of

Preventive \&

Community Dentistry

Publication of International Society of Preventive and Community Dentistry
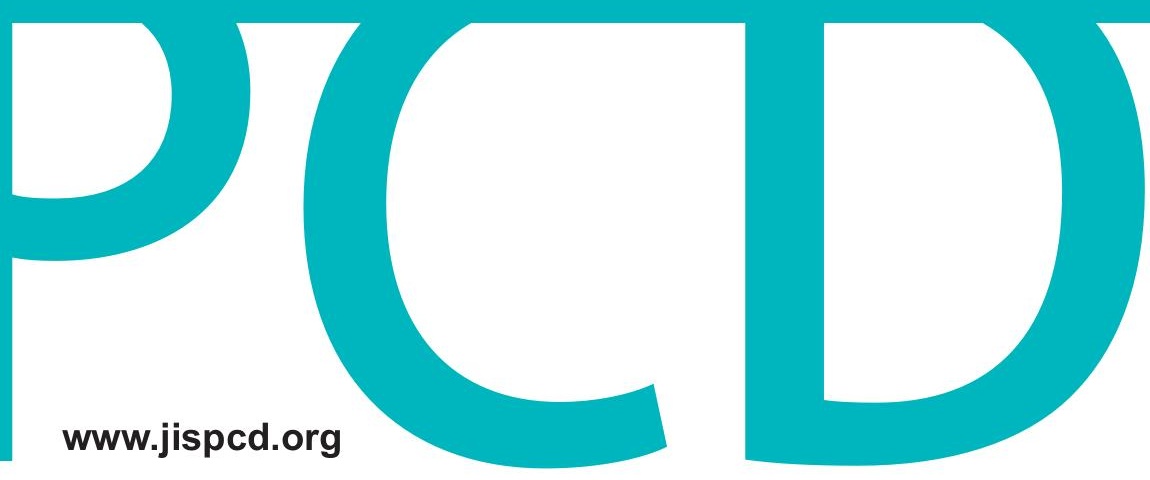


\section{Black hairy tongue in a patient with amyotrophic lateral sclerosis}

\section{Matteo Erriu, Francesca Maria Giovanna Pili, Gloria Denotti, Valentino Garau}

Department of Surgical Science, Cagliari University, Cagliari, Italy

Corresponding author (email: <matteoerr@gmail.com>)

Dr. Matteo Erriu, Dipartimento di Scienze Chirurgiche, Università degli studi di Cagliari, Via Binaghi 4, Cagliari - 09121, Italy.

\section{Abstract}

Black hairy tongue (BHT) is a condition characterized by the elongation of filiform papillae associated with a marked discoloration, from yellowish-brown to black, and a thick lingual coating. BHT is usually observed in the elderly and in patients with limited self-sufficiency, as a consequence of poor oral hygiene. In this perspective, the patients affected by amyotrophic lateral sclerosis (ALS) represent a high-risk category for the occurrence of BHT. The fast and inexorable loss of their self-sufficiency due to progressive muscle atrophy as well as the impropriate education of healthcare assistants have demonstrated to have significant reflection on the maintenance of an adequate standard of oral hygiene. This paper firstly described a case of BHT in a patient affected by ALS. A case of BHT in a patient (Caucasic, male, 63 years old) affected by ALS was described. The primary goal of the work was to teach and motivate the patient to the use of the tongue cleaner in association with the local application of chlorexidine $0.20 \%$. Furthermore, in order to support the patient with accurate domiciliary oral hygiene, a proper training for his health-care assistant was provided. The maintenance of the oral health of ALS patient is fundamental to prevent systemic complications that could jeopardize the already fragile physical balance of these patients. The dedicated monitoring by a dentist or a dental hygienist would seem essential in order to achieve this objective.

Key words: Amyotrophic lateral sclerosis, black hairy tongue, hairy tongue, oral hygiene

\section{INTRODUCTION}

Amyotrophic lateral sclerosis (ALS) is a dramatic neurodegenerative disease resulting from the degeneration of the upper and lower motor neurons in the brain and spinal cord. It is characterized by progressive functional deficits, including a gradual muscle atrophy and weakness of limbs, and decreased respiratory functions. ${ }^{[1,2]}$ The quality of life of ALS patients is further compromised by disorders of speech articulation and intelligibility, which can occur since the earliest stage of the disease. ${ }^{[3]}$ Due to

\begin{tabular}{|l|l|}
\hline \multicolumn{2}{|c|}{ Access this article online } \\
\hline Quick Response Code: & Website: \\
\hline & www.jispcd.org \\
\cline { 1 - 2 } & \\
\hline & DOI: \\
\hline
\end{tabular}

disturbances in muscular control, dysarthria may also be correlated with disproportionate tongue impairment and the development of macroglossia. ${ }^{[3-5]}$

Black hairy tongue (BHT) is a benign condition characterized by marked hypertrophy and elongation of filiform papillae on the dorsal surface of the tongue, consequently to defective desquamation of the epithelium. The hair-like appearance is generally associated with different extent of discoloration,

This is an open access article distributed under the terms of the Creative Commons Attribution-NonCommercial-ShareAlike 3.0 License, which allows others to remix, tweak, and build upon the work non-commercially, as long as the author is credited and the new creations are licensed under the identical terms.

For reprints contact: reprints@medknow.com

How to cite this article: Erriu M, Pili FM, Denotti G, Garau V. Black hairy tongue in a patient with amyotrophic lateral sclerosis. J Int Soc Prevent Communit Dent 2016;6:80-3. 
varying from yellowish-brown to black, and thickness of tongue coating. Although the etiopathogenesis of this kind of lesion has not been fully elucidated, several precipitating factors have been taken into consideration. In particular, prolonged antibiotic therapy, graft-versus-host-disease (GVHD), bad habits (principally excessive tobacco smoking), xerostomia, and poor oral hygiene, have been described in literature as predisposing factors. ${ }^{[6-9]}$ In addition, the discoloration is thought to be related to the overgrowth of microorganisms, such as porphyrin-producing chromogenic bacteria or Candida spp. ${ }^{[10]}$ as well as to a nonspecific infection. ${ }^{[10,11]}$

This report firstly describes a clinical case of BHT in a patient affected by ALS. In this circumstance, the overall rapid progression of muscle weakness, in conjunction with the loss of self-sufficiency, has played a crucial role for its occurrence, as they prevent the patient from the maintenance of an adequate oral hygiene standard.

\section{CASE REPORT}

A 63-year-old Caucasian man was first admitted to the Neurology Department in 2012, with a diagnosis of ALS with generalized exordium (El Escorial Criteria). Since the early stages, the patient showed the symptoms, such as limb weakness, fasciculations of the extremities and the tongue, a marked dysarthria and dysphagia, reduced tongue mobility, sialorrhea that progressed to a significant weight loss. In addition, the initial involvement of the respiratory muscles, and the subsequent difficulty in breathing (dyspnea), required noninvasive mechanical ventilation at night.

During a routine checkup in August 2013, the neurologist identified a black lesion on the lingual dorsum [Figure 1], complicated by the presence

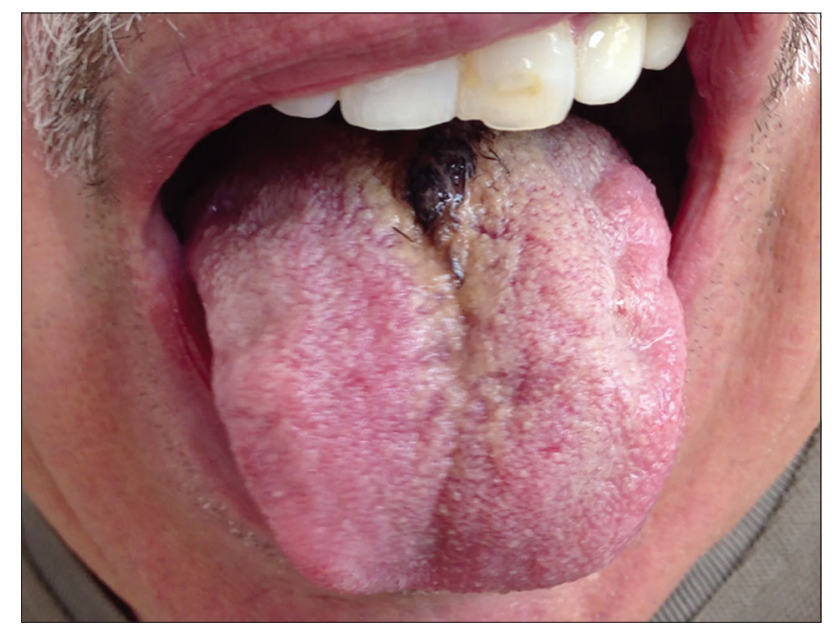

Figure 1: Lingual aspect at the first observation of the BHT by the oral pathologist of halitosis, which is a major cause of a severe impairment of interpersonal relationships. Moreover, the partial hypermobility of the tongue and a reduced self-sufficiency prevailed upon the neurologist to consult the oral pathologist in order to identify the lesion and to establish an appropriate therapy. The clinical examination conducted to diagnose BHT is predominantly related to a tragic reduction of the domiciliary oral hygiene of the patient and the hypofunctional tongue. According to the tongue-coating index by Gómez et al., ${ }^{[12]}$ the tongue lesion was therefore classified as a coating score 2 (heavy-thick coating) and discoloration score 4 (black) of the distal $2 / 3$ of the tongue. Furthermore, the high plaque index (more than $60 \%$ ) and a lack of adequate preparation of the health-care assistant to the oral hygiene procedures specific to the patient's condition were evaluated.

First of all, in order to maintain adequate oral hygienic conditions, the oral hygienist provided the patient and the health-care assistant with the correct oral hygiene protocols to adopt [Table 1]. ${ }^{[13]}$ Specifically, on the basis of the work by Danser et al., the oral clinician focused on and explained the appropriate approach to brush the tongue. ${ }^{[14]}$ The mechanical removal of the coating through the use of a tongue scraper, in association with the daily application of a sterile gauze impregnated with chlorhexidine $0.2 \%$, was crucial.

After 1 month, complete remission of the lesion was achieved, despite the worsening of tongue mobility and further reduction of the self-sufficiency of the patient [Figure 2].

\section{DISCUSSION}

BHT represents a relatively uncommon condition, causing great concerns in affected individuals, due

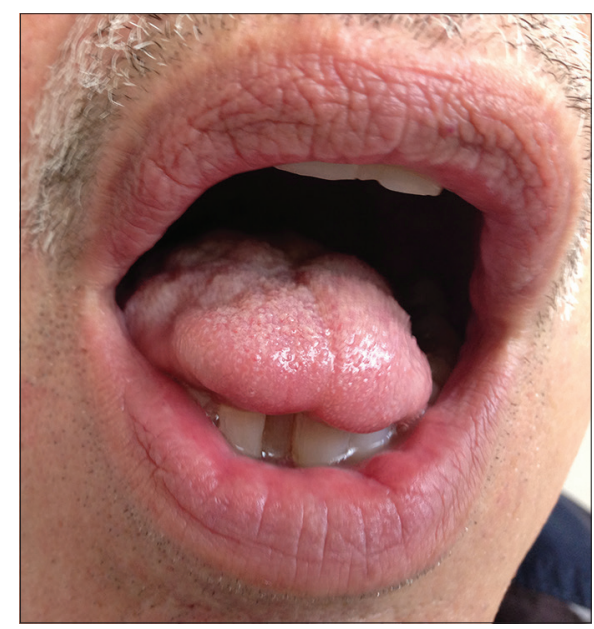

Figure 2: Lingual aspect after the improvement of the oral hygiene 


\begin{tabular}{|c|c|c|}
\hline \multicolumn{3}{|c|}{ Domiciliary oral hygiene protocol } \\
\hline Step & Tools & Description \\
\hline $\begin{array}{l}\text { Tooth } \\
\text { brushing }\end{array}$ & $\begin{array}{l}\text { Tooth brushing } \\
\text { and interdental } \\
\text { brushes }\end{array}$ & $\begin{array}{l}\text { Modified Bass technique and } \\
\text { cleaning of interdental spaces } \\
\text { performed by the health-care } \\
\text { assistant }\end{array}$ \\
\hline $\begin{array}{l}\text { Tongue } \\
\text { scraping }\end{array}$ & Tongue cleaner & $\begin{array}{l}\text { Scraping of the lingual dorsum } \\
\text { from the posterior aspect to the } \\
\text { anterior aspect of the tongue }\end{array}$ \\
\hline $\begin{array}{l}\text { Tongue and } \\
\text { mucosal } \\
\text { disinfection }\end{array}$ & $\begin{array}{l}\text { Sterile gauze } \\
\text { and mouthwash }\end{array}$ & $\begin{array}{l}\text { The sterile gauze was impregnated } \\
\text { with a chlorhexidine } 0.20 \% \text { based } \\
\text { mouthwash and rubbed on the } \\
\text { tongue and mucous membranes }\end{array}$ \\
\hline
\end{tabular}

to its clinical presentation. Although the etiology remains unclear and multiple contributing factors have been considered, the selected individuals have demonstrated to be mainly exposed to a higher risk of developing BHT. In particular, elderly patients with poor oral hygiene as well as those with limited self-sufficiency have been recognized as predominately predisposed. ${ }^{[7]}$

The maintenance of good oral hygiene and the gentle debridement of tongue surface assume a crucial role in the prevention of local and systemic diseases. In particular, on the basis of the current knowledge, the effectiveness of the removal of tongue coating represents an essential prerequisite for preventing bacterial colonization. ${ }^{[14,15]}$

Since an alteration of oral or systemic ecosystem can favourite the development of a pathologic condition, several studies emphasised the importance of oral hygiene procedures in order to mantain the microbial equilibrium into the oral niches. ${ }^{[15,16]}$ According to the literature, the removal of lingual coating can prevent the establishment of periodontal infections ${ }^{[12]}$ as well as systemic complications. In 2008, Abe et al. investigated the presence of Pneumoniae spp. in the lingual biofilm, supporting the necessity of interventions to decrease the risk of respiratory affections in elderly patients. ${ }^{[17]}$ Moreover, in 2013, Santos et al. described how the ventilated patient can incur more easily into a pulmonary infection in the presence of a bacterial colonization of the lingual dorsum. ${ }^{[18]}$

ALS patients represent a high-risk population for such complication, due to the need of mechanical ventilation for respiratory muscles involvement, and the prevention of lingual pathologies becomes indispensable to preserve their general health. ${ }^{[17,18]}$ Despite receiving close medical attention, the critical conditions of ALS patients, especially those with bulbar onset, often divert the attention from the clinical evaluation of oral health. Furthermore, conditions, such as glossitis, periodontal diseases, caries, stomatitis, and the development of halitosis, frequently remain undiagnosed, due to the inability of the patient to communicate discomfort and pain as described in the literature about the patient affected by other kinds of neurological diseases. ${ }^{[19]}$

\section{CONCLUSIONS}

Since the earliest phases of the ALS, the dedicated support of the oral hygienist would be helpful for the maintenance of proper oral hygiene, and specifically tongue hygiene, in order to prevent further local and systemic complications for these patients. ${ }^{[17]}$ In addition, raising awareness about the risk of developing oral pathologies, that could worsen the prognosis of ALS patients, would contribute to improve their quality of life. ${ }^{[20]}$ The education of the health-care assistant about clinical consequences of lacking oral hygiene as well as the standardization of oral health protocols in critical conditions would provide great benefits to these patients. Throughout the years, the use of adequate hygiene devices and daily tongue brushing have been proved to be the best preventive and therapeutic measures, to reduce the amount of pathogenic microorganisms in the oral niches and, therefore, to prevent the systemic complications related to the decline of the oral ecological balance.

\section{Financial support and sponsorship}

Nil.

\section{Conflicts of interest}

There are no conflicts of interest.

\section{REFERENCES}

1. Chio A, Logroscino G, Traynor BJ, Collins J, Simeone JC, Goldstein LA, et al. Global epidemiology of amyotrophic lateral sclerosis: A systematic review of the published literature. Neuroepidemiology 2013;41:118-30.

2. Pugliatti M, Parish LD, Cossu P, Leoni S, Ticca A, Saddi MV, et al. Amyotrophic lateral sclerosis in Sardinia, insular Italy, 1995-2009. J Neurol 2013;260:572-9.

3. Tomik B, Guiloff RJ. Dysarthria in amyotrophic lateral sclerosis: A review. Amyotroph Lateral Scler 2010;11:4-15.

4. McKee HR, Escott E, Damm D, Kasarskis E. Macroglossia in amyotrophic lateral sclerosis. JAMA Neurol 2013;70:1432-5.

5. Yunusova Y, Green JR, Greenwood L, Wang J, Pattee GL, Zinman L. Tongue movements and their acoustic consequences in amyotrophic lateral sclerosis. Folia Phoniatr Logop 2012;64:94-102. 
6. Khasawneh FA, Moti DF, Zorek JA. Linezolid-induced black hairy tongue: A case report. J Med Case Rep 2013;7:46.

7. Kannan S, Muthusamy S, Chandrasekaran B, Gopal D, Sidhu P. Black hairy tongue in older edentulous individuals. J Am Geriatr Soc 2014;62:992-4.

8. Thompson DF, Kessler TL. Drug-induced black hairy tongue. Pharmacotherapy 2010;30:585-93.

9. Akay BN, Sanli H, Topcuoglu P, Zincircioglu G, Gurgan C, Heper AO. Black hairy tongue after allogeneic stem cell transplantation: An unrecognized cutaneous presentation of graft-versus-host disease. Transplant Proc 2010;42:4603-7.

10. Sheikh Z, Khan AS, Khan S. Lingua villosa nigra. Lancet 2011;377:1183.

11. Manabe M, Lim HW, Winzer M, Loomis CA. Architectural organization of filiform papillae in normal and black hairy tongue epithelium: Dissection of differentiation pathways in a complex human epithelium according to their patterns of keratin expression. Arch Dermatol 1999;135:177-81.

12. Mantilla Gomez S, Danser MM, Sipos PM, Rowshani B, van der Velden U, van der Weijden GA. Tongue coating and salivary bacterial counts in healthy/gingivitis subjects and periodontitis patients. J Clin Periodontol 2001;28:970-8.

13. Wainwright J, Sheiham A. An analysis of methods of toothbrushing recommended by dental associations, toothpaste and toothbrush companies and in dental texts. Br Dent J 2014;217:E5.

14. Danser MM, Gomez SM, Van der Weijden GA. Tongue coating and tongue brushing: A literature review. Int J Dent Hyg 2003;1:151-8.

15. Roldan S, Herrera D, Sanz M. Biofilms and the tongue: Therapeutical approaches for the control of halitosis. Clin Oral Investig 2003;7:189-97.

16. Pili FM, Erriu M, Piras A, Garau V. Application of the novel method in the diagnosis and treatment of median rhomboid glossitis Candida-associated. Eur J Dent 2014;8:129-31.

17. Abe S, Ishihara K, Adachi M, Okuda K. Tongue-coating as risk indicator for aspiration pneumonia in edentate elderly. Arch Gerontol Geriatr 2008;47:267-75.

18. Santos PS, Mariano M, Kallas MS, Vilela MC. Impact of tongue biofilm removal on mechanically ventilated patients. Rev Bras Ter Intensiva 2013;25:44-8.

19. Cicciu M, Matacena G, Signorino F, Brugaletta A, Cicciu A, Bramanti E. Relationship between oral health and its impact on the quality life of Alzheimer's disease patients: A supportive care trial. Int J Clin Exp Med 2013;6:766-72.

20. Amou T, Hinode D, Yoshioka M, Grenier D. Relationship between halitosis and periodontal disease-associated oral bacteria in tongue coatings. Int J Dent Hyg 2014;12:145-51. 